\title{
Study on the E-learning Model Based on Japanese Teaching in Colleges and Universities
}

\author{
Hua Wang \\ School of Foreign Studies, Xi'an University, 710065
}

Keywords: College Japanese; Teaching; E-leaning model; Study

\begin{abstract}
The present era is the era of network, and the network plays a role in promoting social development. As the network is widely applied in various fields of the society, the application of network has brought some challenges to education, especially for Japanese teaching in colleges and universities. The application and development of E-learning model in teaching change the traditional classroom teaching model, which has a certain influence on teachers and students in Japanese teaching and learning, respectively. This paper mainly analyzes the form and characteristics of E-learning of Japanese, and focuses on the transformation of E-learning model, including the influence of E-learning platform, E-learning community and MOOC system on Japanese teaching.

With the continuous expansion and development of China's opening-up pattern, the absorption and introduction of foreign culture, as well as to improve the comprehensive quality of talents, the Japanese major has become an important subject in colleges and universities. According to relevant statistics, about 600 colleges and universities have set the Japanese major. However, for the society, the Japanese major is regarded as a major for needs of language, rather than as an academic major, thus scientific study on the Japanese literature, Japanese education and such is ignored. The practice has proved that only all-round learning and development of the academic contents can enable us to master the academic contents effectively and train more and more excellent applied talents to promote social progress.

Before the arrival of the network era, it is the traditional teaching model that plays a role in teaching system in China, and the new online teaching model brought about by the network is a huge challenge to the traditional teaching model. Traditional classroom teaching model is often limited to the teaching time, location and the number of students, and cannot achieve better teaching objectives. However, in the network environment, the E-learning and traditional learning models are combined to avoid the deficiency of traditional teaching model and to develop the advantages of E-learning model, expending the teaching space and platform, thus enabling quick adaption to the reform of education and teaching.
\end{abstract}

\section{Forms and Characteristics of E-learning of Japanese}

Forms. The Network Sharing of Teaching Courseware. Network sharing refers to sharing of the teaching resources through the network among teachers and students. Japanese teachers are the initiator of sharing; they make courseware which involves the learning contents through PPT, FLASH and other technologies, and then deliver it to the sharing cyberspace which includes but is not limited to QQ group, microblog or learning community for teacher-student interaction. In daily learning, students will carry out preview and review of learning content based on curriculum requirements, so as to understand and master the knowledge, which is a supplement to the Japanese language teaching in the classroom.

Online Dictionary. Dictionary is an important tool for students to learn a foreign language. The arrival of the Internet era changes the form of dictionary which is mainly hard copy. The development of online dictionary provides more convenient conditions for students to learn Japanese. Google translation, Youdao translation or Sanseido Dictionary are online dictionaries. Moreover, in order to facilitate the use of the online dictionary, the supplier developed the clientend software of the online dictionary, especially the mobile phone APP, which make the use of Japanese online dictionary more convenient. 
Professional Learning Website. The professional learning website provides a platform for strengthening Japanese language learning. The professional learning websites include some microblogs on Japanese language learning or some Chinese websites which are mainly used for learning of Japanese. The contents of the professional learning website on one hand are related to the daily expression of Japanese, which include basic, practical and recreational curriculum resources. On the other hand, the contents also involve the resources for study in Japan and business negotiations. These websites provide materials which can be downloaded and platform for exchange among online users, promoting the further sharing of resources through the community in the form of Japanese language forum.

Online Broadcasting. Broadcasting is a common form of media in our life. The foreign language online broadcasting has an important impact on the improvement of foreign language listening. Online broadcasting can increase our sense of foreign language and generate foreign language context for better understanding of the meaning of foreign language, facilitating the more efficient and faster learning of a foreign language. TBS is the most representative Japanese online broadcasting station, which is favored by Japanese language learners.

Corpus. The corpus provides systematic and a large number of Japanese language learning resources. A variety of Japanese learning resources are present in the corpus, and these resources are free of charge, allowing learners to freely and infinitely download and use. Aozora Bunko is one of the most representative corpuses in Japan, which is a high-quality E-library.

Characteristics. Asynchronism. In the traditional classroom teaching, students need to understand and master the knowledge while teachers are teaching; this teaching model is synchronous. In the new E-learning model, the teaching and learning can be asynchronous. This model greatly reduces the students' dependence on teachers, so that students can learn by themselves. When students encounter difficulties in self-learning, they can solve the problem quickly through online or offline communication with teachers. In addition, the E-learning model is not limited to time and space, enabling students to learn anytime and anywhere.

Repeatability. Due to the limitations of teaching time in the classroom, students cannot repeatedly practice to reinforce the knowledge, which greatly reduces the degree of students' understanding on the knowledge. The E-learning model, taking advantages of sharing and diversity of courseware resources, allows students to practice and reinforce the knowledge repeatedly, and make full use of a variety of resources, such as pictures, text, audios and videos, so that the teaching effect will be more significant.

Collaboration. The exchange and cooperation between learners is an important advantage of Elearning. The virtual learning community attracts a large number of network users who have the common learning needs and interests. They gather in this community and share excellent learning materials; on the other hand, they can communicate comprehensively on learning difficulties, obstacles and experiences to achieve emotional resonance and common progress.

Intellectualization. The E-learning model not only plays an important role in promoting learning, but also provides convenience to the teachers. The emergence of distance education is the further development of E-learning model. Teachers can use the computer and such other technologies to implement distance education, explain the knowledge and assign and check the homework through the network, achieving intellectualization of teaching as well as allowing students no longer subjected to limitation of teaching time and location.

\section{The Change of Japanese E-learning Model}

The rapid development of Internet technology has greatly changed our learning model. In addition to the ordinary learning models, E-learning has gradually become an important way for people to learn knowledge, and is widely used in university education. E-learning, sharing of network learning space, MOOC system and so on are the new learning models in university education, which are the innovation and upgrading of the traditional learning model.

E-learning Platform. The emergence of E-learning model is a major change for the existing teaching model. This learning model is based on Internet technology and makes full use of the 
external environment and changes in real time. It is based on a variety of digital technologies, meets a variety of learning needs, and ultimately promotes learning. The features of this learning model include, first, rich and diverse learning content consisting of digit integrated by multimedia technology; and second, some scenes in the learning process are completely virtual, and learners can complete the study in virtual environment; third, the participants in the entire learning model include learners, teachers and experts of related areas, which form the learning community. This learning model breaks the constraints of time and space, enabling resources of different regions to achieve complementation. The learners can obtain the most advanced and the latest learning resources by their own choice, and choose the teacher and learning content they like. Moreover, the learning model takes full advantage of the Internet with low cost, fast delivery of information, and unparalleled superiority.

Therefore, based on the E-learning model, the teachers can construct the E-learning platform for Japanese language teaching taking into account the characteristics and current situation of Japanese language teaching, so as to promote the development of Japanese language teaching and enhance the teaching effect. According to the related researches, this paper believes that the platform should include the following subsystems:

Subsystem of Educational Administration. Subsystem of educational administration can achieve enrollment, selecting courses, score inquiry, evaluation and other functions. This subsystem is set for the needs of learners, and adjusts the curriculum in a timely manner according to the actual need.

Subsystem of Teaching Management

This system is mainly set for the teachers. In the process of daily teaching, the teachers need to answer questions, teaching, assigning and correcting homework, which need to be carried out in the teaching management subsystem, thus providing personalized teaching. In addition, this system adds a module for online editing, which can timely modify and adjust teaching resource according to the teaching needs to ensure the normal proceeding of teaching.

Subsystem of Learning Management. The related functions of this system are set for learners, which can achieve a lot of personalized functions for learners. Learners can choose the learning content and speed according to their needs and ability, thus the needs of different learners can be met, providing great convenience for the learners.

Subsystem of Teaching Quality Test. This system is for the guarantee and assessment of the teaching outcomes, which monitors the learning and teaching effects in real time through the functions of homework correcting and evaluation to ensure the teaching outcomes.

Subsystem of Intellectual Property Protection. In the E-learning platform, the intellectual property of the instructors is adequately protected, and the property right is defined and free of violation through the functions of permission setting and such.

Subsystem of Community Exchange. In this system, E-learning platform participants can communicate interactively through e-mail, setting up discussion groups and so on.

E-learning Community. The E-learning community is the study group set based on the network by a group of learners with the common needs for knowledge and learning interests. In this group, participants discuss with each other and exchange ideas, achieving common progress and growth. Learning through the Internet has become an important way to learn. Learners of different ages from different regions with common learning objectives gather by means of the Internet to achieve the sharing of knowledge. Different learners have their own roles in this learning community and communicate with each other to acquire knowledge.

The main function of the community for Japanese language learning is to improve the Japanese language level of the members. In addition, participants share and exchange their experiences in Japanese language learning in the community, which is a huge wealth for others. In the community, most of the Japanese learners are very purposeful; they learn Japanese to go abroad, so the exchange of experience in going abroad in the community has become an important part of the learning content; the experience of the foregoers is extremely valuable. In addition, in the Japanese learning community, false advertising is inevitable to be spread in the community, so the 
information managers need to reinforce the check and management of information to ensure the harmonious development of the community.

MOOC System. MOOC system is an instant online course development system. The traditional course development system focuses on the release of resources and learning management with limited scale, but MOOC system emphasizes on the massive course development, which integrates a lot of learning management systems and network resources. In addition, in the MOOC system, the learners have a greater degree of autonomy and freedom. A number of learners participating in the MOOC system simultaneously will be conducive to large-scale sharing of knowledge and experience. At present, there are many MOOC platforms, among which the Coursera platform is the largest platform with the best development, which have a number of well-known courses of many universities in the world with far-reaching impact.

With further development and popularization of the MOOC system, Japanese language will be involved in the MOOC system, so we must prepare in multiple aspects. First of all, we should select high-quality teaching resources, enhance the screening and selection of Japanese teaching resources, select high-quality and free teaching resources and systematically combed them to meet the requirements of MOOC system. Second, we should be cautious to select the teachers; the teachers should have rich teaching experience and novel teaching methods, as well as be able to adapt to teaching online and attract students' attention.

\section{Conclusion}

The rapid development of network technology has promoted the rapid change of Japanese language teaching model. Japanese language teaching should also conform to the development of online teaching model and make full use of the advantages of network technology, providing diverse, modernized and personalized teaching services to learners to meet the requirements of the new era.

\section{References}

[1] Li X. Exploring the Japanese network teaching platform based on Black Board--Take"Japanese" BB network teaching platform as an example[J]. Journal of Juamjusi Education Institute, 2014, 02:383-384.

[2] Anderson N, Carolyn T, Hajhashemi K, Xiao JH. Improving online learning through the use of design thinking[J]. Distance Education in China, 2014, 09:5-12+95.

[3] Chen YX. An Empirical Study on the Application of Autonomous Teaching Model in Japanese Teachin $[\mathrm{J}]$. Journal of Mudanjiang Teachers College (Philosophy Social Sciences Edition), 2012, 03:136-137.

[4] Gou Y, Zhao XW. Research on the Course Construction of "University Computer Foundation" Based on MOOC Platform[J]. Journal of Inner Mongolia Normal University(Education Science Edition), 2015, 03:148-150.

[5] Jin H,Lan LN. MOOC Promotes Higher Education Reform and Innovation - Interview with Professor Pang Dingquan, Senior Consultant of Hong Kong University of Science and Technology[J]. The Chinese Journal of Ict in Education, 2015, 19:7-11+25.

[6] Liu Y, Zhou L, Liu K, Hu JW. Research and Practice on the Construction of Online Open Course - A Case Study of "Information Theory Foundation" Course in Hunan Agricultural University[J]. Journal of Agricultural University of Hebei (Agriculture and Forestry Education), 2016, 02:106-108.

[7] Hu J, Cui NP, Ding Y. Research on the Online Teaching Mode Based on the National Open University Learning Network - Taking "Mathematical Culture" as an Example[J]. Journal of Shandong Radio and TV University, 2016, 03:23-28.

[8] Li LL, Gao P. A Discussion on Learner Autonomy under Internet Language-teaching Model-A Survey on the Use of Autonomous Learning System for DUT Postgraduates[J]. Computerassisted Foreign Language Education, 2007, 06:68-72.

[9] Chen B, Li XH. Instructional Design: from Distance Education to the Second Generation Online 
Learning[J]. China Educational Technology, 2011, 02:1-5.

[10] Pan HY, Luo ZL. A Probe into the Present Situation of Primary Teaching in Japanese and the Innovation of Teaching Method - A Case Study of Japanese Majors in Oriental Science and Technology College of Hunan Agricultural University[J]. Journal of Xiangtan Normal University (Social Science Edition), 2009, 06:165-167.

[11] Shi L, Cheng G, Li C, Wei SP. A Study on the Learning Behavior of Large-scale Private Online Course and Its Influencing Factors - A Case Study of the Network Course of National Open University[J]. Distance Education in China, 2017, 04:23-32+80.

[12] Sun XW. Online learning behavior analysis based on SPOC platform log data and influencing factors[J]. Journal of Shenyang Normal University(Natural Science Edition), 2017, 01:103-107. 